\title{
THE EFFECT OF IMMUNOLOGICAL ENHANCERS ON SPECIFIC IMMUNITY OF INFECTIOUS BURSAL DISEASE VIRUS USING VIRAL CHALLENGES TESTS
}

\author{
MONA AL. SHARABI \\ PhD of Poultry Diseases, Faculty of Vet. Med., Al-Baath University, Hama, Syria
}

Received: 12 February 2017; $\quad$ Accepted: 30 March 2017

\begin{abstract}
The study was conducted on (100) commercial broiler chickens, for study the effect of Brewer's Yeast on Specific Immunity of infectious bursal disease (IBD) after using challenges tests. The study has confirmed that there were clear significant variations between control and study group which added to its feed Brewer`s yeast during all stages of breeding for antibody titers of IBD ( $\mathrm{P}$ value $=0.01)$. at 34dayold, $(\mathrm{P}$ value $=0.002)$. at 42, dayold.
\end{abstract}

Key words: Immunological, Enhancers, Infectious Bursal Disease, Challenges Tests.

تأثير المحننات المناعية على المناعة النوعية لفيروس مرض الجراب المعدي باستخدام اختبارات التحدي الفيروسية

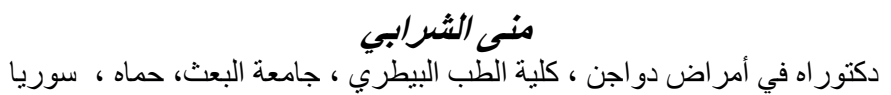

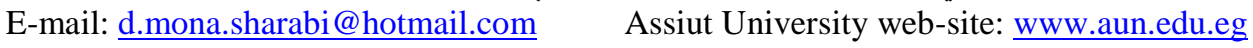

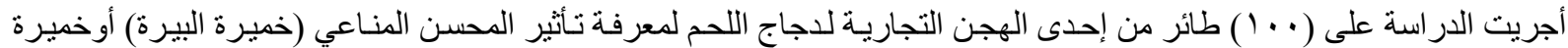

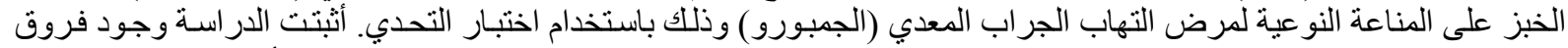

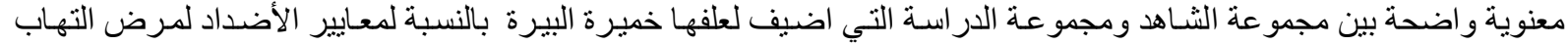

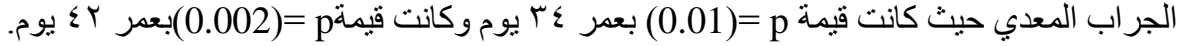

الكلمـات المفتاحية: النيكلوتيدات النوويـة، (nucleotides) ، خميرة الخبز او البيرة (Brewer`s Yeast)، ( Saccharomyces (Cerevisiae)، المناعة النو عية عند دجاج اللحم (Specific, Immunity of Broiler Chickens)

\section{INTRODUCTION}

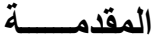

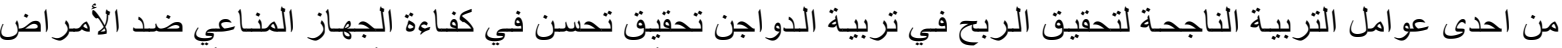

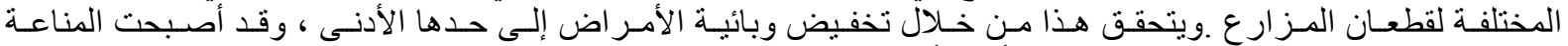

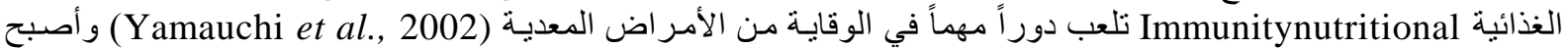

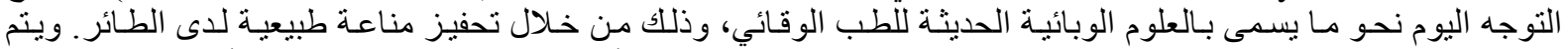

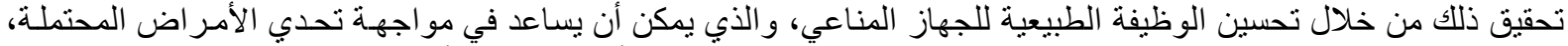

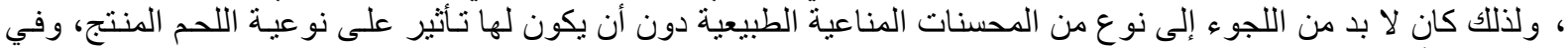

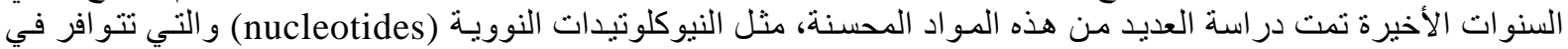

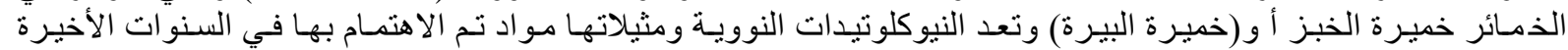

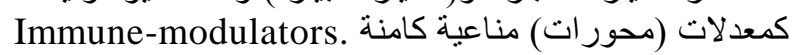

في تلعب دور اً في العديد من الوظائف الفسيولوجية الأساسية بما فيها تثكيل المعلومات الور اثيـة Genetic informations

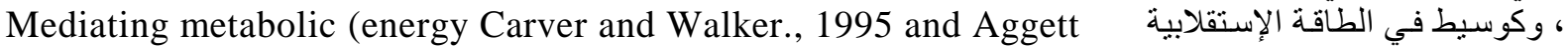

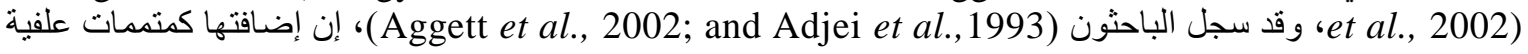

Corresponding author: Dr. MONA AL. SHARABI

E-mail address:d.mona.sharabi@ hotmail.com

Present address: Poultry Diseases, Faculty of Vet. Med., Al-Baath University, Hama, Syria 
يمكن أن يحرض ويحسن المناعة الخلوية الوسيطة Van Buren et al., 1983) Cell -mediated immunity) ، ويؤودي

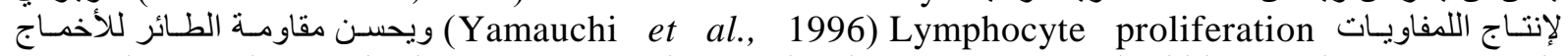

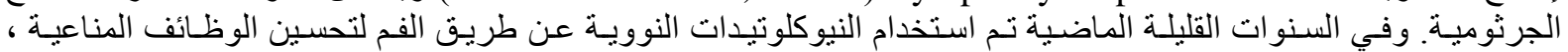

وتحسين فعالية اللقاح ، ومقاومة الأمر اض. الماض.

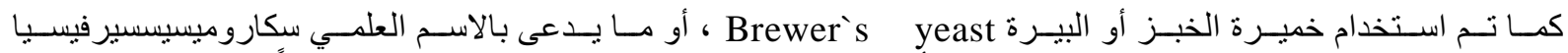
. Saccharomyces Cerevisiae

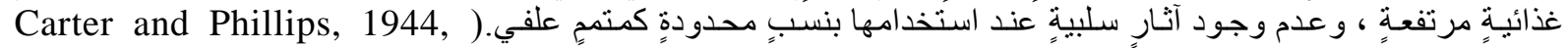

.(Bhattacharjee, 1970

كما وجد الباحث (Stone, 1998) ، أن استخدام خميرة سكاروميسيسسيرفيسيا في تغذيـة دجاج اللحم كمـادةٍ طبيعيةٍ توفر الفيتامينات وخاصة مجموعة فيتامين B وكذلك البروتين ذو القيمة البيولوجية العالية.

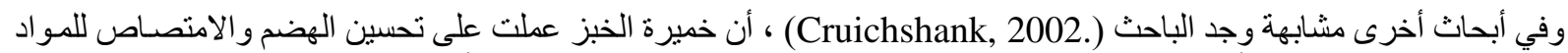

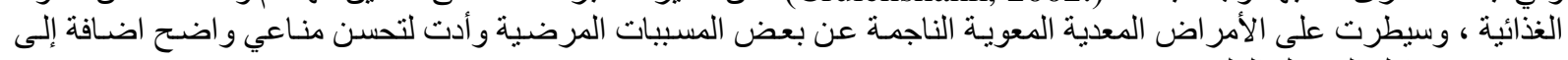
تحسن في معامل التحويل العلفي.

كما وجد الباحثون (Mickolos et al., 2003) أن مشـاركة التحصين مع اعطاء محسن مناعي ، أدى لزيادة في مستوى معيار

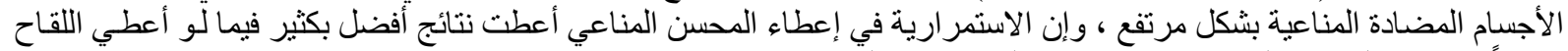

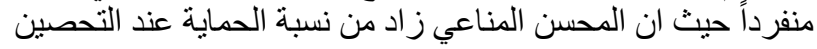

\section{MATERIALS AND METHODS \\ المواد والطرائق}

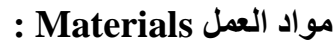

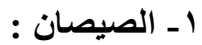

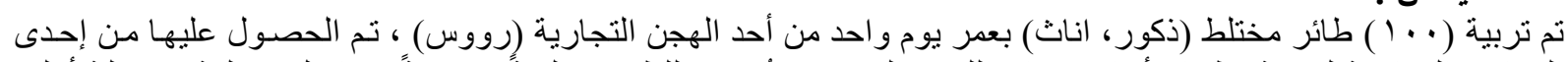

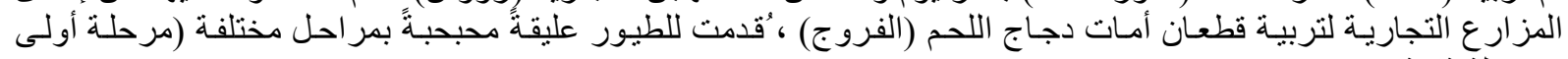

ومرحلة ثانية) .

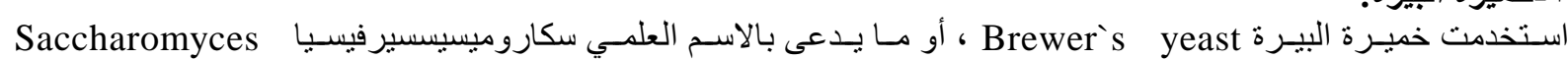

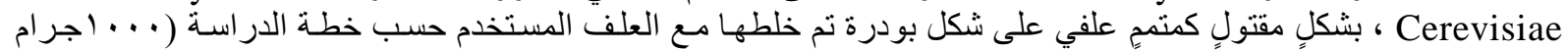

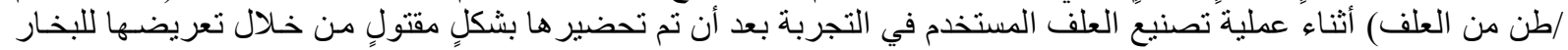

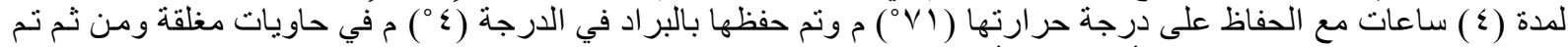

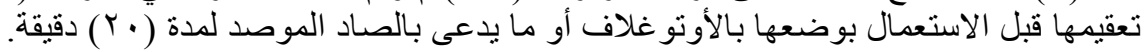

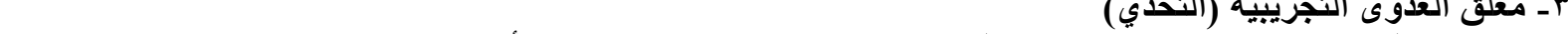

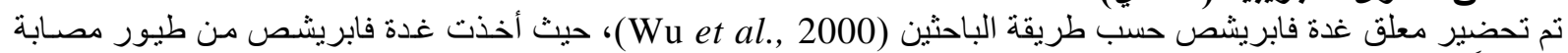

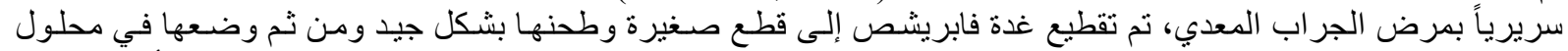
HBSS

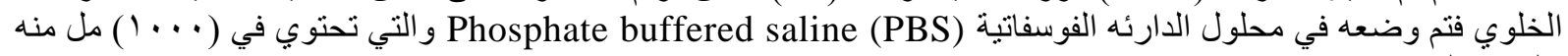
على مأ يلي:

(8.00g NaCl, 0.20g KCl,2.89g Na2HPO4.12H2O,0.20g KH2Po4,PH 7.2) وحضن في درجة حر ارة الغرفة لمدة خمس دقائق لتحلل الأنسجة الخلويـة بعد ذلك ألك أخذ المعلق الخلوي الناتج عن الراسب

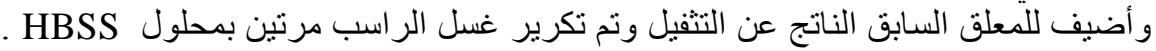

طethods : طرق العمل 1 - مجاميع الدراسة : The Study Groups:

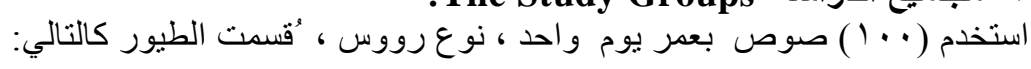
المجموعة الأولى : وهي مجمو عة الشاهد شملت (· ) طير اً قدمت لها عليقةٌ محبحبةٌ خاليةٌ من أي محسن مناعي. 


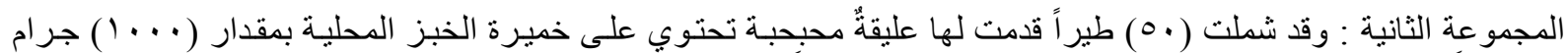

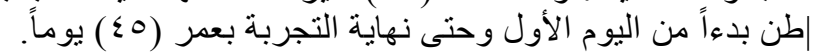

وقد تم تغذية الطيور بعلف محبحب ، وتم مر اعاة الاحتياجات الغذائية حسب متطلبات الطيور في جميع مر احل التربية .فكان

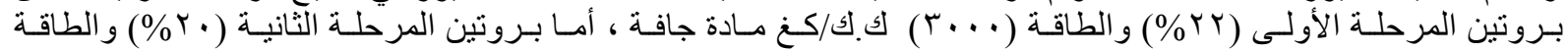
(Y...)

وتم تحصين الطيور لجميع مجاميع الدراسة بنفس جرعة ونوعية اللقاح كما هو موضح بالجدول رقم (1)

$$
\text { الجدول رقم ا : برنامج تحصين طيور التجربة. }
$$

\begin{tabular}{|c|c|}
\hline اسم اللقاح & العمر بالأيام \\
\hline لقاح التهاب القصبات المعدي (حي) العثرة Mas5 عن طريق ماء الثرب & $\wedge$ \\
\hline لقاح النيوكاسلHB1 عن طريق ماء الثرب & 11 \\
\hline لقاح الجمبورو (حي) عن طريق ماء الشرب & 10 \\
\hline لقاح نيو كاسل (حي) CLONE عن طريق ماء الشرب & r^ \\
\hline
\end{tabular}

r بـ بريقة إجراء الاختبار Test procedure:

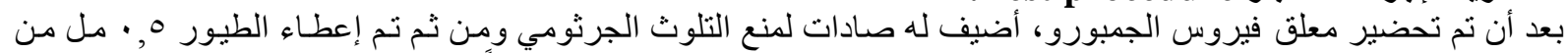

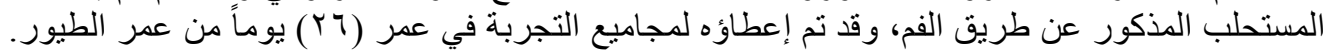

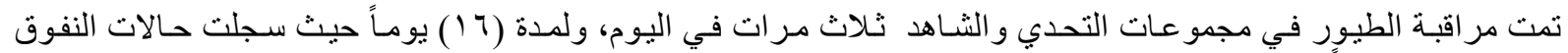

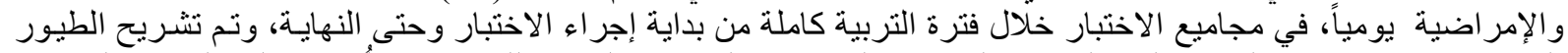

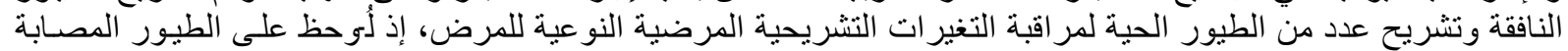

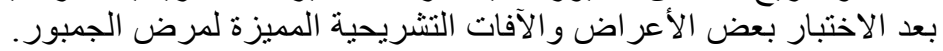

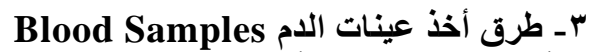

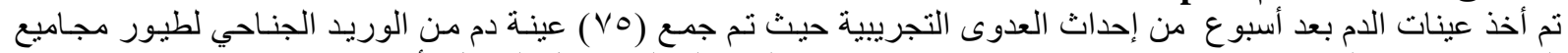

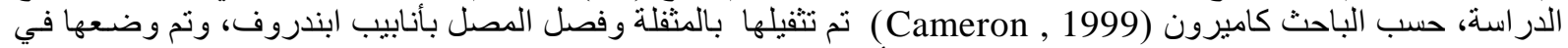

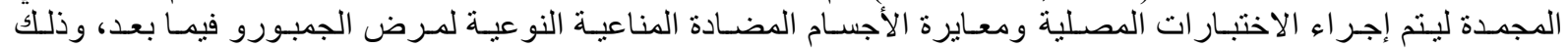

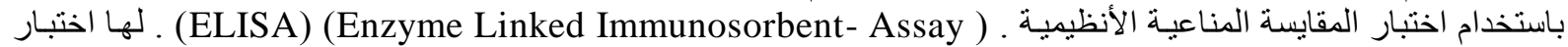
الاليزا. ومن ثم تم أخذ العدد السابق نفسه من عينات الدم بعد الأسبوع الثاني من إجراء العدوى التجريبية (التحدي).

؛ ـ الاختبارات المصلية Serological Tests

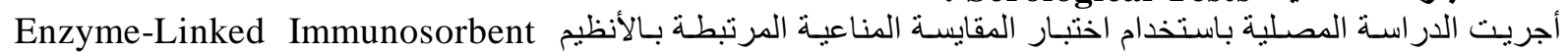
Assay (ELISA)

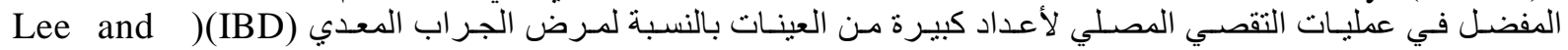

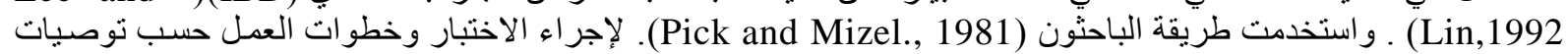
الشركة المنتجة للمجمو عة التشخيصية.

يتم قر اءة طبق الاختبار باستخدام قارئ الاليز ا و على موجة بطول (0 ـ ـ ) نانومتر الذي يقيس معدل الامتصاص في كل حفرة،

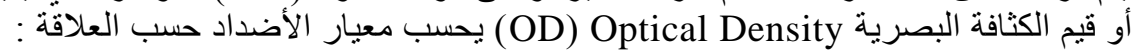

$\mathrm{S} / \mathrm{P}=($ Abs Test Sample - Abs Negative $) /($ Abs Positive - Abs Negative $)$

$\log 10$ Titre $=0.870 X(\log 10 \mathrm{~S} / \mathrm{P})+3.92$

Titre $=$ Antilog of $\log 10$ Titre

هـ طريقة التحليل الإحصائي Statistic Analysis Method

استخدم برنامج التحليل على الحاسوب (Statistics, 1998) ، لإجر اء جميع التحائل الإيل الإحصائية في هذه الدراسة.

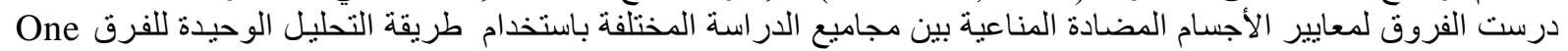

.Way Analysis of Variance 


\section{RESULTS \\ النتائَج}

مقارنة معايير الأَداد لمجاميع طيور العدوى التجريبية ( التحدي) بعمر ع ب يوماً باستخدام طريقة التحليل الوحيدة للفرق: One way - Analysis of Variance (AOV)

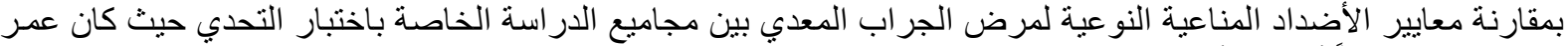

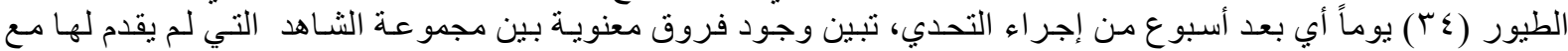

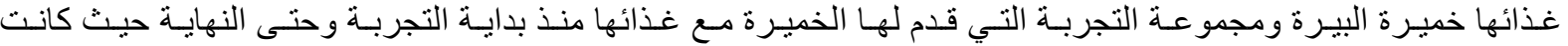

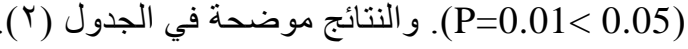

الجدول رقم ץ: مقارنة معايير أضداد مرض الجراب المعدي لطيور مجاميع التحدي عمر الطيور (؟؟) يوماً بعد أسبوع من التحدي.

\begin{tabular}{|c|c|c|}
\hline معايير الأضداد لمجموعة تجربة التحدي & معايير الأضداد لمجموعة شاهد التحدي & المقياس الإحصائي \\
\hline 6088.66 & 3801.66 & المتوسط الحسابي \\
\hline 101.508 & 158.928 & الانحراف المعياري \\
\hline 6233 & 3870 & الوسيط الحسابي \\
\hline 6230 & 3620 & الحد الأدنى للمعايير بالقيمة المطلقة \\
\hline 6403 & 3915 & الحد الأعلى للمعايير بالقيمة المطلقة \\
\hline
\end{tabular}

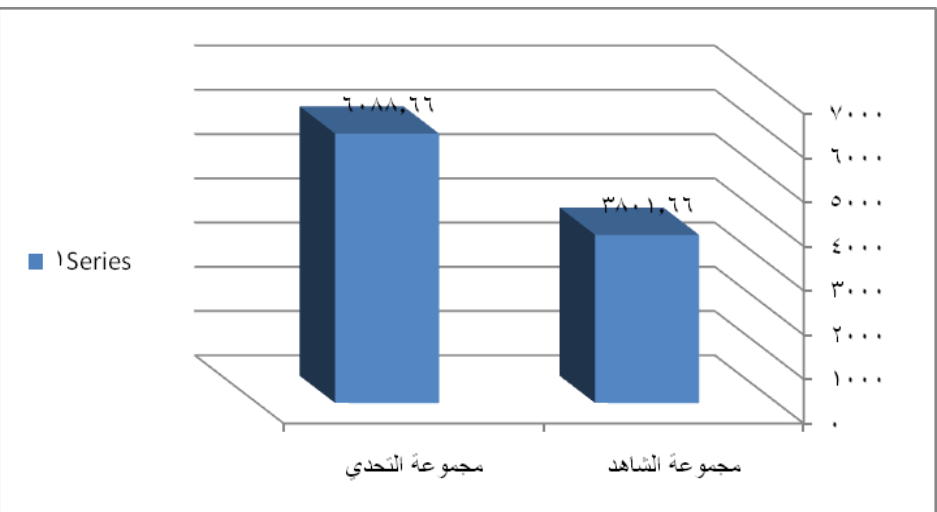

المخطط رقم (1) المتوسط الحسابي لمعايير أضداد مرض الجراب المعدي لطيور مجاميع التحدي عمر الطيور (ع ب) يوماً بعد

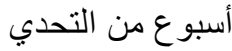

One way - : مقارنة معايير الأَداد لمجاميع طيور التحدي بعمر ب ؛ يوماً باستخدام طريقة التحليل الوحيدة للفرق Analysis of Variance (AOV)

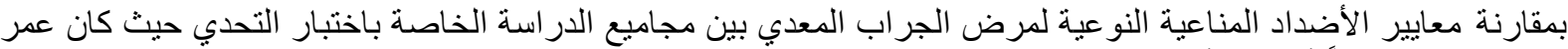

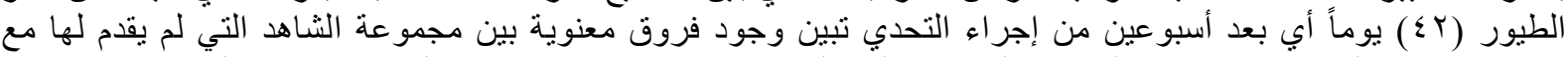

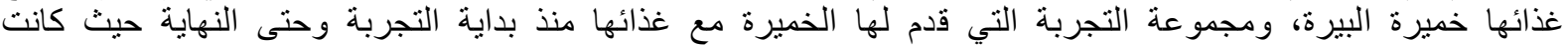

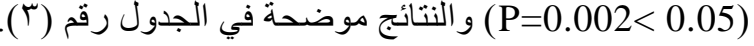

الجدول رقم بّا: مقارنة معايير أضداد مرض الجراب المعدي لطيور مجاميع التحدي عمر الطيور (r؟) يوماً أي بعد أسبو عين من التحدي.

\begin{tabular}{|c|c|c|}
\hline معايير أضداد مجموعة التجربة التحدي & معايير أضداد مجموعة شاهد التحدي & المقياس الإحصائي \\
\hline 7233 & 4673 & المتوسط الحسابي \\
\hline 131.52 & 219.2 & الانحر اف المعياري \\
\hline 7233 & 4673 & الوسيط الحسابي \\
\hline 7140 & 4518 & الحد الأدنى للمعايير بالقيمة المطلقة \\
\hline 7326 & 4828 & الحد الأعلى للمعايير بالقيمة المطلقة \\
\hline
\end{tabular}




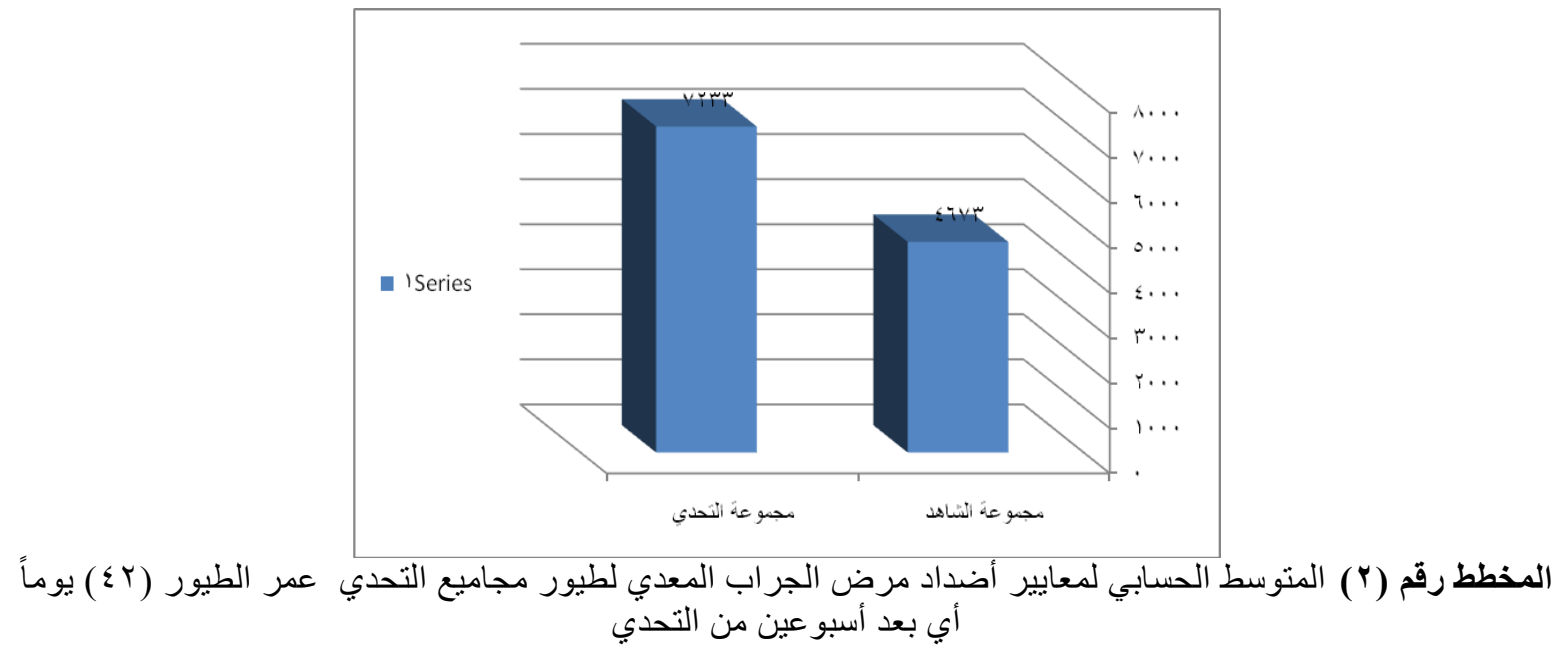

\section{DISCUSSION}

\section{المناقشة}

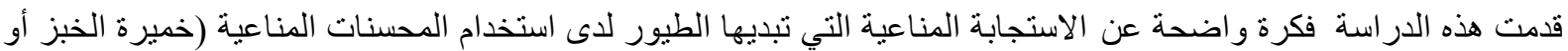

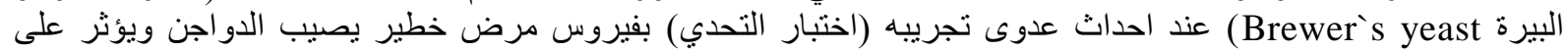
جهاز ها المناعي و هو مرض التهاب الجر اب المعدي.

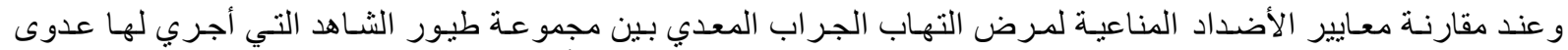

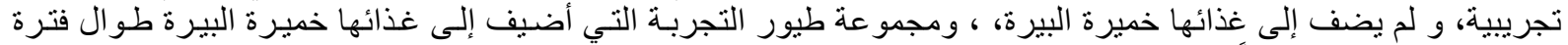

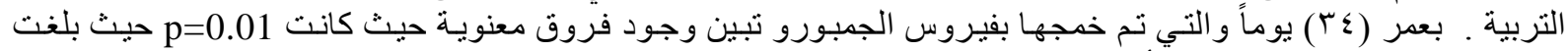

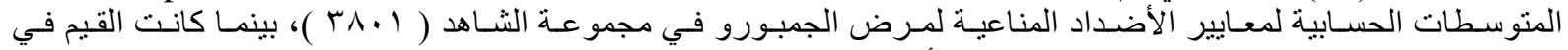

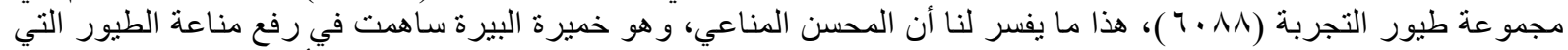

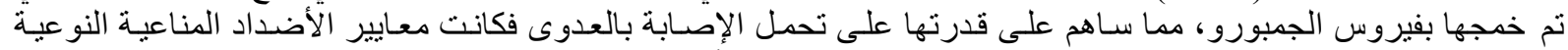

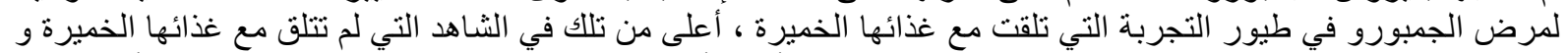

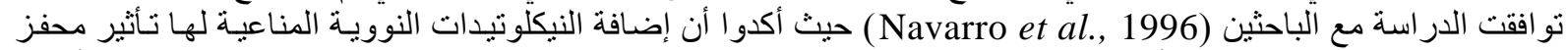

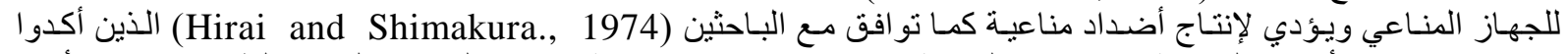

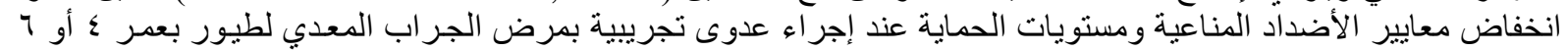

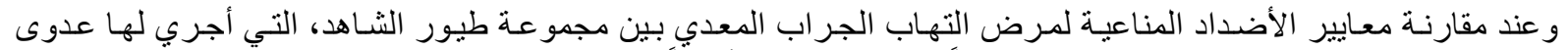

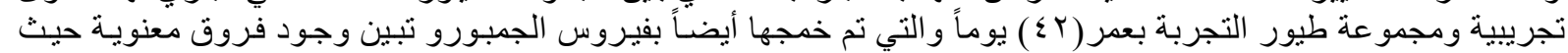

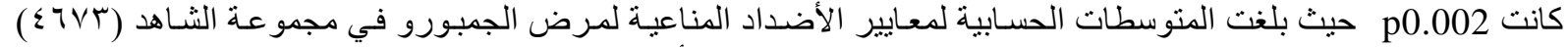

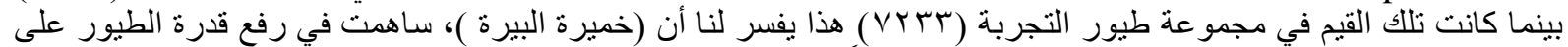

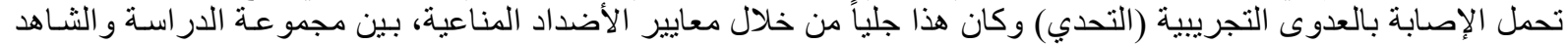

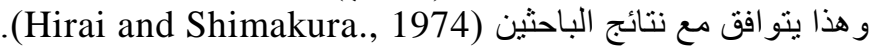

تو افقت هذه الدراسـة أيضـاً مع (Onifade and Babatunde, 1998) حيث أن إضـافة خميرة الخبز تزيد مقاومـة الطائر

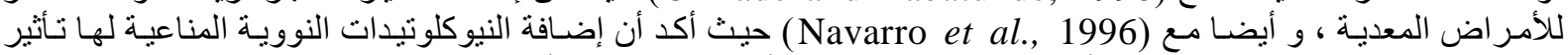

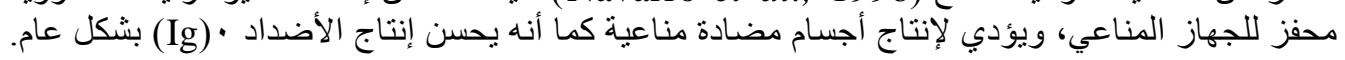

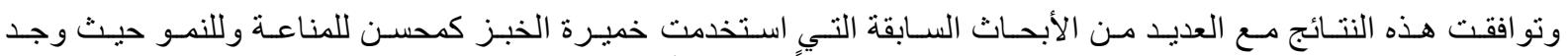
(Yalcin et al., 1993 and Yadav et al., 1994)

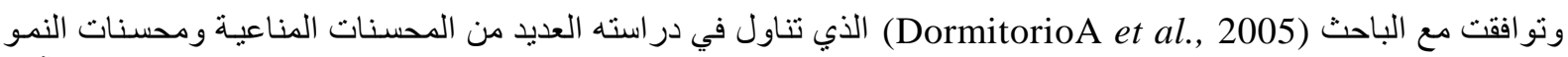

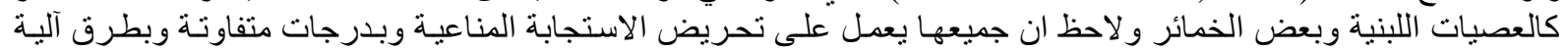
مثقاربة التأثير على الجهاز المناعي. 


\section{CONCLUSION}

الاستتنـاج

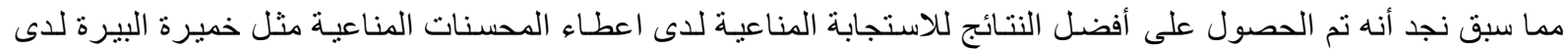

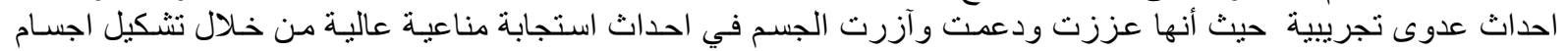

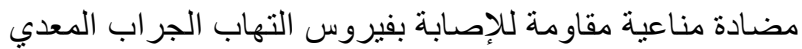

\section{REFERENCES}

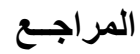

Adjei, A.A.; Takamine, F.; Yokoyama, H.; Shiokawa, K.; Matsumoto, Y. and Asto, L. (1993): The effects of oral RNA and Intraperitoneal Nucleoside- Nucleotide Administration on MethillinResistant Staphylococcus Aureus Infection in Mice. Journal of Parenter Enteral Nutrition. Vol. 17, No. 148-52.

Aggett, R.; Leach, J.L.; Rueda, R. and Maclean, W.C. (2002): Innovation in Infant Formula Development: A Reassessment of Ribonucleotides. Nutrition Journal, Vol. 19, No. 375-84.

Bhattacharjee, J.K. (1970): Microorganisms Potential Sources of food. Adv. Appl. Microbiol. Vol. 13., No. 139.

Cameron, A. (1999): Survey Tool Box for Livestock Diseases: A practical Manual and Software Package for Active Surveillance in Developing Countries. Australian Centre for International Agricultural Research. Australia.

Carter, H.E. and Phillips, G.E. (1944): The nutritive Value of yeast Protiaus. Fed. Proc. Vol.3, No.123.

Carver, J.D. and Walker, W.A. (1995): The role of Nucleotides in Human Nutrition. Natural Biochemical Journal, Vol. 6, No. 58-72.

Cruichshank, G. (2002): Gut microflora the key to healthy broiler growing. Poultry World, July, 14.

Dormitorio A, T.V.; J.J. Giambrone AC; K. Guo A. and D.J. Jackwood B. (2007): Molecular and Phenotypic Characterization of Infectious Bursal Disease Virus Isolates. Avian Diseases 51(2):597-600.

Erf, G.F. (2004): Cell-mediated immunity in poultry. PoultSci, 83:580-590.

Hirai, K. and Shimakura, S. (1974): f infectious bursal disease. virus Viral 14: 957-964. lsaacson,R.E. (eds.) Gastrointestinal microbiology No 2.P 537-587.Chapmanand Hall, New York.

Lee, L.H. and Lin, Y.P. (1992): Amonoclonal antibody capture enzyme - linked Immunosorbent assay for Detecting antibodies to infectious bursal disease virus. Journal of virological methods, 36: 13-23.

Mickolos, D.A.; Fewyer, G.A. and Crotty, D.A. (2003): DNA Science. Cold Spring Harbor Laboratory Press. Publisher, John Inglis. USA.

Navarro, J.; Ruiz-Bravo, A.; Jimenz-Varela and M. Gil, A. (1996).Modulation of Antibody-Forming Cell and Mutagen- Driven Lymph proliferative Response by Dietary Nucleotide in Mice. Immunology Journal, Vol. 53, No. 141.

Onifade, A.A. and Babatunde, G.M. (1998): Comparison of the utilization of palm kernel meal, brewers' dried grains and maize offal by broiler chicks. Br. Poult .Sci., 39: 245-250

Pick, E. and Mizel, D. (1981): Rapid Microassays for the Measurement of Superoxide and Hydrogen Peroxidase Production by Macrophages in Culture Using an Automatic Immunoassay Reader. Journal of Immanuel Methods, Vol: 46:211-26.

Statistics (1998): Analytical Softeware, Guideline manual, Version, 2.0. USA.

Stone, C. (1998): Yeast products in the feed industry. Ed. By Mills, d. Inc. Cedar Rapids, Iowa., p. 1011.

Van Buren, C.T.; Klkarni, A.D.; Schandle, V.B. and Rudolph, F.B. (1983): The Influence of Dietary Nucleotides on Cell-Mediated Immunity. Transplantation Journal, Vol. 36, No. 350-2.

Wu, C.C. Dorairajan, T. and Lin, T.L. (2000): Effect of ascorbic acid supplementation on the immune response of chickens vaccinated and challenged with infectious bursal disease virus. Veterinary Immunology and Immunopathology, 74: 145-152. 
Yadav, B.S.; Srivastava, R.K. and Shukla, P.K. (1994): Effect of supplementation of the broiler ration with live yeast culture onnutrient utilization and meat production. Indian Journal of Animal Nutrition, 11 (4): 225-227

Yalcin, S.; Onol, A.G.; Kocal, D. and Ozcan, I. (1993): The use of baker`s yeast as a protein source in broiler ration. Doga, Turk- Veterinerlik-ve-Hayvancilik-Dergisi, 17 (4): 305-309.

Yamauchi, K.; Hales, N.W.; Robinson, S.M.; Niehoff, M.L.; Ramesh, V. and Pellis, N.R. (2002): Dietary Nucleotides Prevent Decrease in Cellular Immunity in Ground-Based Microgravity Analog. Journal of Applied Physiology.Vol. 93, No. 161-6.

Yamauchi, K.; Adjei, A.A.; Ameho, C.K.; Chan, Y.C. and Kulkarni, A.D. Sata. (1996): A nucleosideNucleotide Mixture and Its Components Increase Lymphoproliferative and Delayed Hypersensitivity Responses in Mice. Journal of Nutural, Vol. 126, No. 1571-7.

Zander, D.V. (1978): In Disease of Poultry (7 ed) Iowa State University Press. PP.3. 